\title{
Group as a Distributed Subject of Knowledge: Between Radicalism and Triviality
}

\author{
Barbara Trybulec \\ Maria Curie-Skłodowska University in Lublin \\ barbara.trybulec@poczta.umcs.lublin.pl
}

Received 18 August 2016; accepted 18 March 2017.

\begin{abstract}
In the paper, I distinguish the bottom-up strategy and the intentional stance strategy of analyzing group intentional states, and show that the thesis of distributed group subject of knowledge could be accommodated by either of them. Moreover, I argue that when combined with virtue reliabilism the thesis satisfactorily explains the phenomenon of group knowledge. To justify my argument, in the second part of the paper, I distinguish two accounts of justification pointing to conditions of group knowledge. The first, which I call the belief-centered approach to group intentional states, determines the concept of group belief and group justificatory reason. The second, the process-centered approach represented by S. Orestis Palermos, employs the theory of virtue reliabilism and focuses on the group knowledge-conducive process. In the paper, I argue in favor of the latter as the internalism associated with the former appears to lack sufficient explanatory power. The theory of virtue epistemology runs into considerable difficulties when trying to deal with an extended epistemic subject composed of one individual and her cognitive artifact. In the two last parts of the paper, I consider the most important difficulties and argue that these obstacles are overcome once one adopts an approach combining virtue epistemology and the thesis of distributed group epistemic subject. ${ }^{1}$
\end{abstract}

Keywords: group agency; epistemic subject; group knowledge; intentional state; cognitive process; distributed cognition.

\footnotetext{
${ }^{1}$ This work was realized as a part of the grant "Sonata" founded by National Science Centre, Poland. The grant's number: 2014/13/D/HS1/00689. The grant's title: "The extended mind thesis and the subject of knowledge."
} 


\section{Introduction}

What do we mean when we say that a group has solved a problem and has an intentional mental state with specific content relating to this solution? We mean that none of the individuals within this group would have been able to solve the problem on their own; what is more, none of the individuals could be solely credited for the group's epistemic success. Hence, as far as virtue epistemology is concerned, the term knowledge refers in this case to a mental state that could be attributed only to a group as a whole, rather to its individual members. In the paper, I will argue that the most reasonable account of group epistemic agency lies somewhere between the radical claim of there being a group mind - a supraindividual entity over and above the organization of individual mental states - and the trivial claim that group level cognition is just solving the problems together. Solving a problem is an intentional activity that requires representing a goal and possible solutions, hence if one assumes that a group can indeed solve a problem, one has to attribute certain intentional states to it. In the first part of the paper, I distinguish two strategies of approaching group intentional states; namely, the bottom-up strategy and the intentional stance strategy. Representatives of the former focus on analyzing how a group's intentional state arises from its organizational structure, while proponents of the later, recognize a group as a unified intentional epistemic subject which, similarly to individual humans, could be analyzed by methods of individualistic epistemology. These two methodological strategies serve different explanatory goals; nevertheless, as I will argue below, they can both adopt the concept of distributed epistemic subjectivity. This concept captures the idea that group intentional states, including knowledge, although not reducible to individual mental states are nonetheless explainable and predictable in terms of the relational structure of group members' beliefs and their relations with cognitive artifacts.

Traditionally, the debate concerning conditions of knowledge has confronted two opposing points of view: internalist and externalist. As far as group knowledge is concerned, I distinguish two accounts of justification which could be related to both sides of the debate. The first, which I call the belief-centered approach to group knowledge, determines the concept of group belief and group justificatory reason. The second, the process-centered approach, employs the theory of virtue reliabilism and focuses on a group knowledge-conducive process. In the second part of the paper, I will argue in favor of the second approach as I conclude that the internalism associated with the former appears to lack sufficient explanatory power. The theory of virtue epistemology runs into considerable difficulties when trying to deal with an extended epistemic subject composed of an individual and her cognitive artifact. In the last two parts of the paper, I consider the most important difficulties and argue that these obstacles are overcome once one adopts an approach combining virtue epistemology and the thesis of distributed group epistemic subject. 


\section{Group as an Epistemic Agent}

To argue in favor of the group knowledge thesis one must firstly justify the more moderate claim of group cognitive agency. What grounds do we have that allow us to attribute intentional mental states such as beliefs and desires to groups? The natural answer is that this strategy is very useful in our everyday practice of explaining and predicting group behavior. Journalists often report that governments make promises, churches maintain certain beliefs, corporations threaten competitors, courts doubt a defendant's guilt and so on. We hold certain organizations morally and legally responsible for their actions and we often ascribe to them psychological states such as humiliation and fear. With respect to group intentional states, eliminativists argue that the expressions mentioned above are merely useful metaphors and do not describe real intentional agents (Quinton, 1975). In their opinion, every statement that refers to a group intentional state could be transformed into a sentence referring to the beliefs and desires of its members. Hence, to recognize certain groups as real cognitive subjects is to confuse metaphorical expression with a literal description. This standpoint represents the mainstream of contemporary analytic epistemology according to which only individuals can cognize and possess knowledge, for epistemology is about things that go on inside the head. ${ }^{2}$

Proponents of this approach argue in favor of a summative understanding of group mental states and maintain that a group belief is just a sum of individual beliefs with the same content. Unfortunately, summative individualism provides neither necessary nor sufficient conditions of group mental states, hence it fails to appropriately explain its meaning. ${ }^{3}$ Furthermore, critics of the summative approach point out that saddling groups with legal or moral responsibility or taking them to the court assumes that they literally, not only metaphorically, intended to commit a crime. The above suggests that explaining group behavior in terms of its members' beliefs and responsibilities is insufficient — an assumption that underlines the ongoing debate over group intentional states. From the ontological perspective the main question is whether there are group cognitive processes which involve states of the group agent itself in addition to mental states of its members. Those who answer this question affirmatively argue that a group itself is an agent that solves cognitive problems and has actual cognitive capacities itself which are analogous to those of individuals and not identical to the cognitive capacities of its respective members. In virtue of the above, a group may be said to be a subject of mental states with intentionality that is original rather than only derived. I propose distinguishing two methodological strategies of

\footnotetext{
2 This is the idea expressed by Alvin Goldman: "Knowers are individuals, and knowledge is generated by mental processes and lodged in the mind-brain" (Goldman, 1992, p. 179).

${ }^{3}$ The detailed critique of the summative account is presented in (Gilbert, 1987). These arguments are summarized in (Trybulec, 2015a).
} 
analyzing this ontological problem. The first, which I call the bottom-up strategy of explaining group intentional states, is less affirmative towards the above question than the second - the intentional stance strategy. ${ }^{4}$

\subsection{Bottom-Up Strategy of Explaining Group Intentional States}

Representatives of the two strategies conceive the aim of their analyses differently. Those who opt for the bottom-up method explain how group intentional states arise from the structural organization of group members' beliefs. They aim to determine the conditions of group intentional states with regard to the features of the relations between particular members' beliefs. In ontological terms, it could be said that these authors analyze the base on which a group intentional state supervenes, and which is composed of intentional states of individuals and their respective interrelations. This is why I called this strategy bottom-up.

Among the most prominent proponents of the bottom-up strategy one could mention Michael Bratman (Bratman, 1999), Raimo Tuomela (Tuomela, 1992, 2011), Margaret Gilbert (Gilbert, 1987, 1996) and Philip Pettit (Pettit, 2007; List \& Pettit, 2011). Bratman and Tuomela do not postulate the existence of supra-individual cognitive agents. Instead, they explain group intentional states in terms of individual intention to share an action or a belief with others within the group. Every intentional state they refer to belongs to individuals or is reducible to the sum of We-intentions or acceptances of individuals. Hence, there is no discontinuity between the members' and the group's intentional states. Unlike Bratman and Tuomela, Gilbert and Pettit seem to be realists as far as group agency is concerned. They use the notion of a group agent to describe the cognitive subject that has its own intentional states which have causal power and are not continuous with the group members' beliefs. According to Gilbert, a group belief emerges from members commitments to act as a single body possessing its own intentional states (Gilbert, 1996). This joint commitment obliges members to undertake concrete joint actions which could be recognized as actions undertaken by a single, unified agent. However, critics of Gilbert's approach argue that she does not sufficiently justify the discontinuity thesis. If a group agent is constituted by interrelated individual commitments, its intentional states can be explained and predicted in terms of individual beliefs and the relations between them (Velleman, 2009). Hence, Gilbert's approach, similarly to those of Bratman and Tuomela, suggests that every member of a group has his own, individual intentional states. All or some of them decide to form a joint commitment to act as a single body, yet this should not be understood as a conjunction of individual minds into a common group mind. Rather, it should be seen as an agreement of all or some group members to accept certain judgments as true and to act accordingly in order to reach a common goal. In other words, it is an agreement of individuals to act as if they were a single, unified agent of beliefs and desires.

\footnotetext{
${ }^{4}$ The distinction between these two strategies was introduced in my previous works under the name of individualism-objectivism (or holism). I have decided, however, that the most accurate names for these methods of analyzing group intentional states are the bottom-up strategy and the intentional stance strategy (Trybulec, 2015a, 2016).
} 
Pettit's argument in favor of the discontinuity thesis is more convincing. A group agent exhibits three features of agency: representational states, motivational states, and a capacity to process them and to act upon them (List \& Pettit, 2011). To satisfy these requirements, a group has to be organized so as to realize certain collective desires according to the group's beliefs. The theory of judgments aggregation is a special field of enquiry that investigates possible ways of aggregating distinct and possibly conflicting intentional attitudes of members into a group judgment. The developments in this theory show that it is impossible to have a procedure for determining group judgments that both accounts for their consistency and is responsive to group members' attitudes. It is called the impossibility result (Pettit, 2007). In a nutshell, if a group chooses a strategy that preserves the consistency of its judgments, some of its judgments could be inconsistent with the actual attitudes of its members. Moreover, such a strategy can be exercised without any of the members receiving feedback on the judgments already made by the group, which means that none of the members know or accept them. Pettit shows that only groups with a rational point of view are able to partly overcome the impossibility result. Such groups possess the ability to evaluate their set of desires and beliefs in terms of rationality. ${ }^{5}$ The procedure of judgments aggregation realized by a group with a rational point of view is complex, yet it ensures that the gap between individuals and group judgments is bridged, at least theoretically. However, does this solution not deprive the group agency thesis of one of its most convincing arguments? The discontinuity between group and individual judgments motivates the thesis of group agency as it implies that it is impossible to explain or predict a group's judgments with regard exclusively to its members' individual decisions. If however, we seek to identify a procedure that secures the members' control over the group's rational performance, the discontinuity between group and individual judgments seems to disappear. Members keep track of their group's judgments and commit themselves to accepting and supporting them, hence the possibility of explaining group attitudes in terms of individual judgments seems to be revived. However, one has to keep in mind that these individual judgments are determined by the group's organizational structure which, in turn, is embedded in social and methodological norms. This is why the group's propositional attitudes cannot be explained solely in terms of individual mental states. I include Pettit's proposal in the bottom-up camp because he conducts detailed analyses of the process of aggregating individual beliefs into group attitudes.

\subsection{The Intentional Stance Strategy of Explaining Group Intentional States}

Proponents of the intentional stance strategy, who are represented in this paper by Deborah Tollefsen and Thomas Szanto, point out that conceptual analyses of a group intentional state, regardless of its complexity, do not define its necessary and sufficient conditions

\footnotetext{
${ }^{5}$ Pettit illustrates the process of overcoming the impossibility result by a group applying a straw-vote procedure (Pettit, 2007).
} 
(Tollefsen, 2002). ${ }^{6}$ Hence, they abandon the bottom-up method arguing that it is possible or even necessary to use the standard notion of an intentional agent in order to explain group behavior. Advocates of the intentional stance strategy are not interested in describing how a group intentional state emerges from its base but rather aim to explain and predict the behavior of a group agent using the standard method of psychology - to interpret groups as individual, real agents. This method is indispensable to the analyses of group behavior, as tracing members' intentional states tells us little about group cognitive performance as such. Applying the intentional stance strategy to groups enables us to easily recognize another kind of agent which, alongside individuals, plays a crucial role in explaining social reality. Without the ability to use this powerful, explanatory strategy, the task of explaining and predicting groups' behavior and their impact on social reality would require a very difficult and time-consuming process of analyzing the members' mental states and their mutual relations determined by the group's organizational structure which, in turn, is based on social, methodological and cultural norms.

In Tollefsen's opinion, to interpret a group as an intentional agent one has to assign it the capacity to reason (Tollefsen, 2004). This means that a group not only has to be able to act according to the norms of rationality, but it also has to exhibit a rational point of view from which it engages in the control and improvement of its rational performance. The structure of certain groups provides a way of synthesizing disparate individual perspectives into a unified rational point of view from which group goals and beliefs are settled. When members of a group make group decisions, accept propositions as group beliefs, plan group actions, and consider their consequences as a group, they deliberate from the group rational point of view. This reflective process is assessed according to the norms of rationality that govern individual cognitive enterprise. ${ }^{7}$ Hence, a group's capacity to reason makes its epistemic performance open to evaluation and critique. Thomas Szanto uses the intentional stance strategy to explain what it means for individuals to share one group mind. Group intentional states, he argues, are properties of a single, rationally unified, mental unit (Szanto, 2014). This unit should not be understood as some substantial entity existing over and above individuals; instead it should be seen as supervening on a normatively and rationally integrated set of individual mental states. This understanding of group agency is close to the distributive account to which I refer in the last part of the paper. For now, all I aim to show is how group agency is explained from the perspective of the intentional stance strategy. Szanto argues that the behavior of some groups observed in social life as well as in designed experiments exhibits manifestations of intentional states such as beliefs about the truth of certain propositions, and desires to reach certain goals. Such groups should be recognized as standard intentional agents as, just like individuals,

\footnotetext{
${ }^{6} \mathrm{An}$ important representative of the intentional stance strategy is also Georg Theiner. I refer to his arguments in my paper (Trybulec, 2016).

${ }^{7}$ An agent is rational if, among others, it does not act contrary to its best judgment, if it draws inductive inferences on the basis of available, relevant evidence, if it believes only things that it takes to be true and does not believe inconsistencies (Tollefsen, 2007).
} 
"They are sensible to norms. They are capable of self-evaluation and correction. They have means of linguistic, symbolic representation. They can communicate, vote, set up rules, deliberate, and can manipulate their cognitive environment. Moreover, they exhibit a complex internal mental architecture (such as an organizational structure, holistic determination of mental content, etc.). What else might we reasonably expect from attributing mental properties to some entity?" (Szanto, 2014, pp. 110-111).

From the perspective of the intentional stance strategy, a group could be an agent of intentional states just like an individual. ${ }^{8} \mathrm{We}$ attribute agency and rationality to a group for the same reason that we attribute it to individuals. This strategy is very effective. It would be extremely difficult to produce an explanation of group behavior in terms of the behavior of the respective group members embedded in complex social relations. The same is true for individual agency which would be extremely difficult to explain in terms of neurophysiological properties. The two strategies described above evidence, each in its own way, that there are genuine group cognitive subjects and this is all I needed to show before presenting arguments in favor of group knowledge. In the next part, I distinguish two approaches relating to this phenomenon: the joint account of group justification exploited by the proponents of the bottom-up strategy, and the reliabilist account developed through virtue epistemology.

\section{The Belief-Centered Approach and the Process-Centered Approach to Group Knowledge}

Knowledge is a special kind of belief. Hence, to determine what knowledge is one has to designate the conditions which a belief has to satisfy to achieve this special epistemic status. As far as group knowledge is concerned, these conditions must apply to group beliefs. Thus, it seems that before reflecting on how a group belief could be justified (assuming that it is true), we have to determine precisely what it is. This strategy, which I call the belief-centered approach to knowledge, seems obvious, yet there is another way of analyzing group knowledge that does not focus on a definition of a group belief. Proponents of the processcentered approach define knowledge not in terms of features that a belief should possess, but by focusing on the characteristics of knowledge-conducive processes. They do not deny that knowledge is a belief, but it is a belief formed in a special way, and this way is exactly what the main focus of group epistemologists should be. I find this strategy more effective in analyzing group knowledge as it evades the difficulties related to attributing a belief to a group while dealing fairly well with explaining what it means that a group knows.

\footnotetext{
${ }^{8}$ One crucial difference between individual and group intentional states is that the second one could not be conscious. Consciousness however is not essential for intentionality (Szanto, 2014).
} 


\subsection{The Belief-Centered Approach to Group Knowledge}

Raimo Tuomela is one of the main proponents of the belief-centered approach to knowledge. He also continues to develop the bottom-up strategy of explaining group intentional states. He argues that knowledge possessed by an individual involves abilities and skills. A knowing person must have reasons for believing the truth of the proposition and must be able to use this proposition in reasoning and action. Hence, he assumes, that knowledge entails justified true belief, although the converse entailment does not hold. ${ }^{9}$ Tuomela's analyses of group knowledge are based on his conception of a group belief which he refers to as the positional account (Tuomela, 1992). In a nutshell, he claims that a group believes a proposition if there are operative members in respective positions who jointly accept the proposition and, because the relevant authority system is exercised, they continue to accept it. Moreover, non-operative members of a group also ought to accept the proposition. Joint acceptance means that members are mutually aware that they accept the proposition in question. Hence, a central notion in Tuomela's account of a group epistemic agency is a normatively binding group belief. The group is obliged to reason and act on the truth of the proposition in question and it also, at least to some extent, fulfills the obligation.

As far as group knowledge is concerned, a group knowing a proposition entails that said group accepts this proposition as true and is justified in doing so, which means that at least the operative members share a justifying joint reason for this proposition. This condition is satisfied on the following conditions: each operative member accepts a certain judgment as a justifying reason for the proposition in question, this judgment is true, and all operative group members accept it as a justifying reason for the proposition in question (Tuomela, 1992). The above formulation is not a definition of a justifying joint reason for it would be circular, it only clarifies the conditions under which a reason is jointly accepted as a group reason. If a reason is not jointly accepted within a group - if group members are not mutually aware that they all accept it - a group might fail to be justified in believing the proposition even if each member is justified in believing the same. Here, we encounter the crucial question of the group agency thesis: is there a continuity between group and members' beliefs? In attempting to answer this, it is necessary to evoke Tuomela's differentiation between private beliefs and acceptances. Without going into unnecessary detail, a group member has to accept a group belief, yet she does not have to believe it privately. Hence, according to the joint account of group knowledge, at least operative members have to jointly accept the proposition in question and its justifying reasons. Under this condition they actually know the proposition, thus it is not possible for a group to know an item that is not known by any member - the continuity between group and members knowledge is preserved (Tuomela, 2011). On the other hand, it is possible that none of the group members privately believe the proposition in question. Thus, as far as the

\footnotetext{
${ }^{9}$ Gettier paradoxes clearly indicate this (Gettier, 1963).
} 
members' private beliefs are considered, a group could be justified in believing the proposition even though no member privately possesses justifying reasons. When analyzing the continuity/discontinuity problem one has to bear its twofold nature in mind.

Tuomela's account points to the internalistic conception of group justification. A group has epistemic access to justifying reasons, for these are joint reasons shared by its members. Joint account of group justification is however limited: it cannot be applied to groups where joint reason is unavailable, for no member controls a belief-forming process and, for this reason, is able to evaluate its epistemic features. In such cases it is more effective to regard a group as an individual subject of knowledge and to evaluate its beliefs using the means of individual epistemology. Such a strategy is being developed by S. Orestis Palermos who incorporates the theory of virtue reliabilism into the discussion on group knowledge.

\subsection{The Process-Centered Approach of Group Knowledge}

S. Orestis Palermos is developing an account of group knowledge from the perspective of virtue reliabilism. How it is possible to make sense of a group as a virtue epistemic agent? According to Palermos, such a possibility arises from the combination of virtue reliabilism and the distributed cognition thesis. As a result, we are presented with a process-centered account of group knowledge that is determined in terms of individualistic epistemology (Palermos, 2016a, 2016b, 2015, 2014a, 2014b).

The distributed cognition thesis is a somewhat more general approach to the nature of mind - the active externalism which regards some aspects of the environment as driving one's cognitive processes. ${ }^{10} \mathrm{~A}$ widely discussed thesis within active externalism is the hypothesis of extended cognition which claims that under the appropriate conditions, cognitive processes literally extend to the agent's environment, including manipulation of artifacts, which enables cognitive processing. ${ }^{11}$ Proponents of the distributed cognition thesis go even further: they claim that a cognitive system could extend to include not only an artifact which an individual agent uses, but also several individuals and their epistemic artifacts (Hutchins, 1995, Theiner \& O'Connor, 2010, Sutton et al., 2008). In other words, a cognitive process could be distributed among several individuals and their epistemic artifacts. To explain what such a distributed cognitive process is, Palermos exploits the dynamical system theory - the mathematical framework for studying the behavior of dynamical systems (Palermos, 2015, 2014b). In brief, a distributed cognitive system requires

\footnotetext{
${ }^{10}$ Active externalism has appeared in the literature under several formulations-e.g., the extended mind thesis (Clark \& Chalmers, 1998), cognitive integration (Menary, 2007), environmentalism (Rowlands, 1999), locational externalism (Wilson, 2004), the hypothesis of extended cognition (Clark \& Chalmers, 1998), the hypothesis of distributed cognition (Hutchins, 1995).

11 "The actual local operations that realize certain forms of human cognizing include inextricable tangles of feedback, feed-forward and feed-around loops: loops that promiscuously crisscross the boundaries of brain, body and world" (Clark, 2007). For the discussion on the extended mind and the extended cognition theses see: (Trybulec, 2014a, 2014b, 2015b).
} 
the existence of non-linear relations that arise out of continuous reciprocal interactions between the contributing parts (Palermos, 2015; Chemero, 2009; Sutton et al., 2008; Theiner \& O'Connor, 2010; Wegner et al., 1985). These relations give rise to new properties of a system that do not belong to its individual parts. This is the theoretical base for the group epistemic agency thesis. The existence of non-linear, cooperative relations between members of a group gives rise to group properties which must be attributed to a group epistemic subject. Individuals within a group mutually adapt their actions and beliefs to each other so as to achieve aims that they are not be able to bring about on their own. Such coordination gives rise to collective properties (behavior, cognitive processes) which cannot be reduced to the properties of individuals.

As I have already noted, Palermos' group knowledge thesis combines the distributed cognition thesis with virtue reliabilism. Hence, it would now be prudent to shed some light on the second component of this thesis. Virtue reliabilism is a position on epistemic justification that incorporates the ability intuition of knowledge into process reliabilism. ${ }^{12}$ Its proponents argue that not every reliable belief-forming process should be counted as knowledge-conducive. Only processes that are appropriately integrated into the subject's cognitive character and as such manifest the subject's cognitive ability eventuate in knowledge (Sosa, 2007; Plantinga, 1993; Greco, 1999, 2007; Pritchard, 2006, 2010). Appropriate integration means that a process interacts cooperatively with the subject's cognitive character. Under this condition, the subject's cognitive success could be, to a significant degree, creditable to his cognitive agency. ${ }^{13}$ A cognitive character is defined as consisting of the subject's organismic cognitive faculties, memory, and overall doxastic system. In addition, however, it can also consist of acquired faculties, "acquired skills of perception and acquired methods of inquiry, including those involving highly specialized training or even advanced technology" (Greco, 1999, p. 287). ${ }^{14}$ Hence, virtue reliabilists stress the importance of the way in which a subject arrives at her true belief. In order to know, a subject must believe the truth because of his cognitive ability, only then can his true belief be creditable to himself. Although this conception of epistemic justification focuses on the subject's epistemic abilities and responsibilities, it remains in line with epistemic externalism. To possess knowledge one need not have access to the reasons justifying one's true beliefs. In other words, a subject does not need to be aware that her belief-forming process is appropriately integrated into her cognitive character, or the reasons for this integration.

\footnotetext{
12 Process reliabilism is formulated as follows: S knows that $\mathrm{p}$, if and only if S's true belief is the product of a reliable belief-forming process (Goldman, 1979).

${ }^{13}$ It is a week formulation of virtue reliabilism that determines only a necessary condition of knowledge: "COGAweak: If S knows that $\mathrm{p}$, then S's true belief that $\mathrm{p}$ is the product of a reliable belief-forming process, which is appropriately integrated within S's cognitive character such that her cognitive success is to a significant degree creditable to her cognitive agency" (Pritchard, 2010, pp. 136-137).

${ }^{14}$ The reason why virtue reliabilists stress the creditable nature of knowledge and its origin in the agent's cognitive ability is to prevent knowledge-undermining epistemic luck involved in Gettier cases. "When one's true belief is the product of the manifestation of one's ability then believing the truth cannot have been lucky" (Greco, 2007, p. 58).
} 
Palermos notices that there are knowledge-conducive processes that cannot be attributed to one individual. In such cases, knowledge eventuates from a process that is distributed among many individuals and cannot be reduced to the sum of their cognitive agency. According to Palermos, the process-centered account is better designed to explain thus understood group knowledge than the alternative belief-centered approach. Although group intentional states are very useful in explaining group behavior, it is hard to argue in favor of their genuine existence. The reason is that group intentional states are reducible to the members' beliefs and their organizational structure (Palermos, 2014a). This is also true as far as epistemic justification is concerned. As I have shown in the previous paragraph, Tuomela's justifying joint reason must be jointly accepted by at least the operative group members, hence a group cannot possess knowledge that is not possessed by at least some of its members. On the contrary, the process-centered account presents group knowledge as a product of social interactions between individuals which cannot be reduced to the members' mental states and creditable to the sum of their cognitive characters (Palermos, 2016a, 2015). Such a reduction is precluded by the fact, that relations between contributing members are non-linear and reciprocal, which are the essential features of a dynamic distributed cognitive system. Proponents of a process-centered account based on virtue epistemology focus rather on features of a belief-forming process than on features of a belief itself. Hence, they claim that a group, as a single agent, can have knowledge, not because the relevant proposition is a specifically determined group belief, but because getting to the truth of this proposition could only be achieved by the group as a whole, and is thereby creditable only to this group as a whole. This argument justifies the need to incorporate the notion of a group subject of knowledge into epistemology. A group epistemic subject possesses distributed cognitive character that consists of distributed cognitive abilities which are the products of socio-epistemic interactions between the group members. Since a group is regarded in this position as a self-standing agent, its distributed epistemic activity, which is distinctively social, could be explained in terms of individualistic virtue epistemology. An experiment conducted by a research team could be an example of such a distributed subject of knowledge (Palermos, 2015). The knowledge-conducive process within a complex experiment is distributed among experts that engage in dense interactions. Hence, the resulting knowledge is creditable, and thus attributable, to the group's cognitive agency as a whole rather than the individual researchers alone. Here, we encounter a rather counterintuitive conclusion that none of the researchers themselves know the proposition that expresses the knowledge distributed in the group. The continuity between the knowledge of the group and its members is broken and the resultant gap constitutes the very reason justifying the group knowledge thesis.

Palermos does not explain what it could mean that a group possesses a belief that is not possessed by any of its members. He argues that his account of group knowledge does not need such explanation and should be distinguished from such analyses (Palermos, 2015). Clearly, Palermos agrees that knowledge involves a belief and that, in the case of group knowledge, a belief should be qualified as a belief of a group. Yet, he argues that the group knowledge thesis does not need to determine what a group belief is and how it arises from 
the members' intentional states and their relations. A group possesses knowledge not because a relevant proposition is irreducibly and justifiably believed, but because a knowledge-conducive process can only be conducted by the group as a whole and as such the resulting knowledge is creditable to the group's cognitive character, rather than the cognitive character of any of its members taken individually. Obviously, an individual can also come to know a proposition that is the result of a group knowledge-conducive process. However, although both the individual and the group are aware of the relevant proposition, their knowledge is not the same. The crucial difference is the process via which an agent achieves knowledge. An individual can know the proposition on the basis of a testimonial chain initiated by scientific knowledge of a research team. However, the scientific process of getting to the truth of this proposition for the first time can only be attributed to the group as a whole. ${ }^{15}$ The justification for the final result has a distributed nature and no individual could formulate the same on his own. To sum up, a knowledge-conducive process is attributed to the group as a whole, hence a group can qualify as an epistemically responsible self-standing subject of knowledge.

Palermos's group knowledge thesis assumes an externalistic conception of justification. As in the case of individuals, a group subject of knowledge does not need to have any beliefs regarding the reliability of its belief-forming process. A group is justified in holding a belief provided that its distributed cognitive character is integrated by the members' reciprocal interactions. Hence, a group cognitive character is constituted by the assembly of cognitive abilities of individuals who engage in reciprocal interactions between themselves and their instruments. Therefore, a group's cognitive success, which is the product of such interactions, must be attributed to the structural organization of the members' cognitive faculties and their artifacts, rather than any of their individual cognitive characters alone. In addition, for a group to be justified in holding a proposition, it is required that the members are motivated to believe the truth and that they mutually control the group's cognitive process. This condition enables a group to respond appropriately if a cognitive process is erroneous. Otherwise, if it is correct, a group possesses knowledge without the need to be aware that it does so and that the knowledge-conducive process is reliable (Palermos, 2016b, 2014b).

Virtue reliabilism seems to be a promising account of group knowledge. Its understanding of a group epistemic subject takes the moderate position between the radicalism of strong metaphysical emergentism and the triviality of summative accounts. Yet, virtue epistemology encounters a few serious problems when dealing with extended epistemic agency. In the two following parts of the paper I will consider whether arguments dismissing virtue epistemology as a viable theory of extended knowledge also apply to group knowledge.

\footnotetext{
${ }^{15}$ For analyses of knowledge produced on the basis of scientific experiments see: (Knorr-Cetina, 1999; Giere \& Moffatt, 2003; Giere, 2007).
} 


\section{Virtue Epistemology as a Theory of an Extended Epistemic Subject: Doubts}

Most of the critique voiced against virtue epistemology as a position explaining what extended knowledge is focuses on systems composed of one individual and her cognitive artifact. Below, I present three arguments showing the difficulties faced by virtue epistemology when determining such systems as subjects of knowledge. Subsequently, in the last part of this paper, I will show that virtue epistemology does not encounter these obstacles when dealing with a group epistemic agent. This epistemic theory fits well with the distributive account of group knowledge.

\subsection{Argument from Attributiveness of a Credit to an Intentional Agent}

The first of the selected arguments was formulated by Sanford Goldberg. He argues that cases of acquiring information from artifacts are not good examples of extended knowledge because information processing done by an artifact cannot be subjected to normative epistemic assessment. In Goldberg's opinion, it is only when a subject relies on a source which is an epistemic subject in its own right that a belief-forming process could be regarded as extended, that is including information processing done by the source (Goldberg, 2012). It seems, however, that such an understanding of cognitive extension is different from its original formulation. These are not processes done by a computer or a calculator that are recognized by Clark and Chalmers as constituting a subject's extended cognitive processes, but a subject's manipulation of an external artifact. Hence, it seems that Goldberg's claim could be understood as showing that only manipulation of a source which itself could be susceptible to an epistemic assessment constitutes an extended epistemic process. A manipulation of an artifact, on the other hand, cannot give rise to extended knowledge. Why is that? Goldberg's argument is based on the assumption he refers to as Generic Epistemic Extended Hypothesis (GEEM), which states that proper epistemic assessment of a subject's belief, which is an effect of an extended belief-forming process, requires epistemic assessment of information processing that takes place in the subject's environment (Goldberg, 2012). Now, Goldberg argues, that one cannot evaluate information processing done by artifacts in terms of epistemic assessment (rationality, responsibility), only in terms of reliability. ${ }^{16}$ Hence, an extended cognitive process takes place only in cases of testimonial beliefs when a subject relies on another epistemic subject. In testimony cases, the source of information which a subject "manipulates" itself has a certain cognitive-psychological nature, unlike artifacts which belong to the category of brutecausal (Goldberg, 2012). Why does this matter? Why would relying on a cognitive subject be so different from relying on artifacts as far as knowledge is concerned? Goldberg's answer is that in the case of a testimony, there is a distribution of epistemic responsibility, or, in virtue epistemology's terms, a distribution of epistemic credit. If a testimonial belief

\footnotetext{
${ }^{16}$ Michaelian claims that evaluating artifacts in terms of reliability is a kind of epistemic assessment. The difference between artifacts and intentional agents is that normative assessment of the latter is sensitive to a broader range of factors (responsibility, rationality) than normative assessment of the former (reliability) (Michaelian, 2014).
} 
is to be recognized as knowledge, not only must the subject be epistemically responsible in her reliance on another person, but this person must also satisfy relevant standards. In cases when a subject relies on an artifact, the credit is not distributed as artifacts cannot be epistemically responsible or creditable for an epistemic success. A cognitive character which is responsible for knowledge production is attributed entirely to an individual subject, which means that knowledge is not distributed, but is possessed by the individual. In terms of Goldberg's position, thus understood knowledge is not extended. To recapitulate, knowledge could be attributed only to an intentional agent or distributed only among intentional agents. A system composed of an individual and a cognitive artifact cannot be recognized as a subject of knowledge.

\subsection{The Argument from the Peripheral Role of a Subject's Agency in Distributed Cognitive Systems}

The above critique points out that an extended system composed of a human being and her cognitive artifact cannot be recognized as a subject of knowledge since artifacts cannot share epistemic responsibility and credit with an individual. Unfortunately, Kourken Michaelian and Christian Kelp demonstrate that an individual within an extended system cannot be attributed with these features either. Both of these authors refer to Pritchard's virtue theory, which claims that a subject achieves knowledge only if his cognitive agency makes a significant contribution to the formation of a true belief (Pritchard, 2010). In the case of a system which is composed of an individual and a cognitive artifact, the significance of the individual's cognitive agency is not always clear. To show this difficulty, Michaelian compares two cases of obtaining knowledge from an external source. The first is the famous Clark and Chalmers' Otto case which is recognized as an example of extended cognition (Michaelian, 2014). According to Pritchard, Otto's cognitive agency makes a significant contribution to the formation of his true belief. Otto is responsible for acquiring and setting up the notebook, and also for maintaining his access to the same. Hence, in this type of extended system, the individual's cognitive agency contributes to the selection of the relevant external resources, to the endorsement of information and to the assembly of the whole system as such. In Pritchard's opinion the contribution is significant (Pritchard, 2010). Nonetheless, there are cases of testimonial knowledge in which an individual uses an external resource in a knowledge-conducive process and her agency seems to be minimal. This situation is illustrated by Lackey's example of a tourist who, upon arriving in an unfamiliar city, asks the first person she sees for directions (Lackey, 2007). According to Pritchard, the tourist obtains knowledge only if she can identify the reliable and filter out the unreliable information (Pritchard, 2010). Under this condition, the tourist's cognitive agency makes a significant contribution to the formation of a true belief. However, Michaelian argues that as long as the environment is epistemically friendly, the tourist can achieve epistemic success even if she is not good at selecting reliable informants. In this case, the subject appears to attain knowledge which cannot be credited significantly to her cognitive character. The truth of the belief is due to the truth of the received testimony- 
had the received information been false, the subject would have accepted it anyway (Michaelian, 2014). The same goes for the reliance on artifacts, in many cases the subject's agency does not play a significant role in forming a true belief (for example when the subject forms a belief about the time by looking at a clock). Hence, although there is a class of cases in which the subject's contribution to the formation of a true belief is significant, there are many other cases in which this contribution is minimal, and yet the subject is not deprived of knowledge. This problem leads Michaelian to the conclusion that virtue epistemology is not an appropriate position relative to extended knowledge.

A similar argument against the significance of the subject's contribution to the formation of a true belief is provided by Christoph Kelp (Kelp, 2014). To justify his claim, Kelp focuses on cases in which other people's cognitive abilities play a significant role in attainment of knowledge by the subject. In such cases a cognitive success is not primarily creditable to the subject of knowledge. ${ }^{17}$ Otto's case, as always, is a good example. Imagine that Otto's wife sets Otto up with a notebook. She teaches him how to use it and keeps the system functioning effectively. One day Otto looks at the notebook and comes to believe that he has an appointment with a doctor. Surely, Otto knows that he has an appointment, but his true belief is not primarily creditable to his cognitive abilities (Pritchard, 2010). This and other similar cases show, according to Kelp, that virtue epistemology is powerless as far as the subject's knowledge depends on the contributions of other people. In the next chapter, I will show, that virtue epistemology accommodates these cases with the support of the distributed account of group knowledge.

\subsection{Argument from the Static and Asocial Nature of an Organism-Centered Ex- tended System}

Even if the proponents of virtue epistemology can show that epistemic credit, and hence knowledge itself, could be attributed to an individual within an extended system, they will be exposed to another serious problem noticed by Edwin Hutchins. Clark argues in favor of the hypothesis of organism-centered cognition. When he explains how information is recruited and how an extended system is maintained, he gives precedence to the human brain (Clark, 2008). Although Clark decentralizes control and indicates a fragmented and distributed mix of self-organizing processes, he still locates these processes inside the human brain. Proponents of applying virtue epistemology to cases of extended knowledgeconducive processes often follow Clark in this respect and emphasize an individual as a subject of epistemic knowledge. Edwin Hutchins argues, that an organism-centered extended system is static and asocial, and that to prevent it from being so, it is necessary to recognize self-organizing processing of such a system as distributed throughout all of the

\footnotetext{
${ }^{17}$ The condition of knowledge stating that a cognitive success must be primarily creditable to the subject has been formulated by Pritchard and Vaesen (Pritchard, 2010; Vaesen, 2011).
} 
system's processes, including the socio-cultural processes in which the system is embedded (Hutchins, 2011). Yet, if the biological brain is no longer considered as the central element in an extended cognitive system, what else assembles it, what is responsible for its maintenance? Hutchins ventures that an important role in this respect is played by cultural practices and to justify this claim he refers, unsurprisingly, to Otto's case. He shows that Clark and Chalmers' analysis of Otto's situation is not adequate for two reasons. Firstly, they depict the cultural world, in this case the notebook, as static and inert. Secondly, they describe Otto and the notebook as isolated from society. Contrary to this scenario, Hutchins points out that Otto's capacity to use the notebook as an external vehicle of memory is constrained by cumulatively evolved cultural practices transmitted in society. ${ }^{18}$ Hence, a biological brain is not the only factor responsible for constructing a cognitive system, much of the work is done by other processes, including cultural practices distributed throughout the system. Hence, if epistemologists aim to explain knowledge of extended systems, they should focus not on the human component of such systems but on thei social and cultural constituents. ${ }^{19}$

All of the three critiques presented above undermine the position of virtue epistemology as an effective theory of an extended subject of knowledge. Their representatives point mainly to the problem which could be boiled down to the question of to whom (what) epistemic responsibility, credit, and character should be attributed. The acceptance of these three critiques leads to the conclusion, that neither an individual nor an extended system as a single unit seems to be an appropriate candidate for the subject of these features. Goldberg observes that epistemic credit could only be attributed to an intentional agent, hence extended systems composed of one individual and her cognitive artifact cannot constitute one single subject of knowledge. Michaelian and Kelp argue, on the other hand, that an individual within an extended cognitive system does not always make significant contributions to the formation of a true belief, hence he cannot be recognized as the subject of knowledge. Yet, as shown by Hutchins, even if he could be recognized as such, he would, together with his artifacts, form a system which is static and asocial and as such has very little in common with real extended cognitive systems embedded in the social world. In the last chapter, I will show that virtue epistemology deals well with these critiques when applied to the problem of group knowledge.

\footnotetext{
${ }^{18}$ A similar point has been made by Sterelny: "The most critical, mind-and-brain-shaping environ- mental supports for cognition are these cumulatively built, collectively provided tools for thinking, tools that are provided to many or all of a generation by many or all of the previous generation" (Sterelny, 2010, p. 479). Thanks to an anonymous referee for the "Avant. Trends in Interdisciplinary Studies" for raising this point.
}

${ }^{19}$ The Clark-Hutchins debate is considered in detail in (Kirchhoff \& Newsome, 2012). 


\section{Virtue Epistemology and a Distributed Group Epistemic Subject}

I do not plan to evaluate the critiques evoked in the previous chapter and decide whether virtue epistemology can account for the subject of knowledge constituted by one individual and an artifact. My aim in the last part of the paper is to argue that in conjunction with the thesis of the distributed epistemic subject, virtue epistemology constitutes a promising theory of group knowledge which overcomes said objections.

How can a group, for example a research team, know something? A good example in this case is provided by Karin Knorr-Cetina (1999). She points to the process of knowledge production in the High Energy Physics experiment at CERN and argues that the size, complexity and duration of the experiment make it impossible to be controlled by one or even several researchers. The participants in this experiment are jointly and intentionally engaged in solving a problem, yet they rarely share their knowledge with each other and they do not come together to agree on a common view. They have their own areas of expertise and communicate with others only for the purposes of local coordination. Nonetheless, as a result of their organization and with the help of cognitive instruments, they produce knowledge which cannot be attributed to any of them individually, but it must be possessed by some epistemic subject. This subject is constituted by the group. Hence, one can say that CERN knows how to isolate 38 atoms of antihydrogen even if none of its members know how to do it. How can a group composed of many individual epistemic subjects constitute one single cognitive unit that knows something? The distributed account of group knowledge is designed to explain this phenomenon. But the crucial question is whether it can explain not only production, but also the group's possession of knowledge. Can knowledge as a mental state be distributed? Can a group constitute a distributed subject of mental, intentional states? My answer to these questions is positive. The knowledge of a group is distributed among individuals, their interrelations and cognitive artifacts. It can also be explained as supervening on this base. How can virtue epistemology accommodate the idea of distributed epistemic subject? I will show this by responding to the critiques evoked in the previous section; yet before doing so, I would like to focus on a serious problem concerning the supervenience relation.

The issue I am undertaking goes all the way back to Jaegwon Kim (1988). He argues that, according to the supervenience thesis, all the causal work is done by the realizers of functional states - hence supervenient mental states - are epiphenomenal, and as such they do not play any explanatory role. When we apply this thesis to the case of group mental states, we have to face the conclusion that since all the causal work is done by the attitudes of individuals, group mental states are causally inert, and if so, they should be abandoned as explanatory superfluous. Yet, is it really so? Under the assumption that causal explanation is the only type of explanation, the reference to group mental states is indeed redundant. One can satisfactorily explain group behavior in terms of individual psychological processes within a particular social organization (Wilson, 2001). The notion of supervenience is employed by functionalists in order to explain the relation between multiply realizable 
mental states and their realization base. Group propositional states are also multiply realizable. The group belief that "We should merge with another corporation" could be realized by many different companies (Tollefsen, 2015). Even if it were possible to explain why Lucky Strike merged with Camel in terms of intentional states of decision-makers, such a reductionist explanation is insufficient explain why companies, in general, merge under certain situations. The reason is that there may be nothing in common at the level of the realization bases that would explain why different companies act in the same way. The macro-level explanation in social sciences seems to be indispensable; yet, on the other hand, it seems impossible to combine it with a commitment to a stringent notion of causal explanation. The analogous problem appears at the level of individuals. Proponents of non-reductive physicalism who refer to the supervenience thesis are confronted with the claim that mental states are epiphenomenal, and are not causally responsible for the agent's behavior, hence there is no need to posit their existence, and no point to argue in favor of non-reductivism. These problems suggest that reductionism is motivated by a view of causality that is too restrictive, for it rules out certain types of explanations as causally explanatory. Yet, such explanations comprise a large collection of successful explanations in economics, politics, and psychology. If we adopt the criterion of causal explanation that is present, for instance, in the view of Jaegwon Kim, these good causal explanations must be rejected. If, on the other hand, we adopt a less stringent notion of causality, the threat of the superfluity of group intentional states, even under the assumption of their supervenient character, is staved off. ${ }^{20}$

\subsection{Group as a Distributed Intentional Agent}

The first critique formulated by Sanford Goldberg suggested that only an intentional agent is susceptible to normative epistemic assessment and as such is an appropriate candidate for a subject of knowledge. Hence, if one argues in favor of a distributed group subject of knowledge, one should demonstrate that the group's intentional states are distributed throughout it. What could this mean? Firstly, it is important to bear in mind that a group's intentional states are the states of the group itself, in addition to the states of its members. As I have already shown in the first chapter when analyzing the intentional stance strategy for explaining group intentional states, this thesis has been corroborated by severl philosophers. A group is recognized as a genuine subject of knowledge since it is the assembly of individual group members as a whole that initiates and maintains the relevant knowledge-conducive process and that is responsible for it. As indicated by Palermos, the members' reciprocal interactions are what binds them together into a single cognitive entirety and allows a group to control its rational behavior, thus eventuating in knowledge production. Assuming this, I support the view that group knowledge supervenes on the structural organization of individual intentional states and their manipulation of artifacts.

${ }^{20}$ This point is made by Lynne Baker (1995). 
This means, however, that group knowledge is reducible to the intentional states of members reciprocally interacting with each other according to the rules of the group's organizational structure. What I mean by this is that knowing the individuals' beliefs, their social relations, the group's organizational structure and the members' relations with their cognitive artifacts, one is able to explain and predict the group's intentional states. Group knowledge is thus distributed among all of these factors which together constitute a group epistemic subject. I am aware that such a reductive way of explaining group intentional states is highly ineffective. That is why, if one aims to explain and predict a group's behavior, I support the intentional stance strategy. However, this is a practical issue. In theory, group intentional states could be explained in terms of the organizational structure of a group composed of individuals, cognitive artifacts, and reciprocal relations between them. One could doubt, however, that such a claim could be combined with the thesis of group epistemic agency. ${ }^{21}$ To clarify this issue, I would like to express my solidarity with ontological individualism - the view that groups are composed of individual human beings, and do not exist as entities "over and above" these individuals (Tollefsen, 2015). Yet, this position does not imply the thesis that groups do not exist. Likewise, I am nothing "over and above" my physical make-up, but still I like to think of myself as an existing epistemic subject. I am aware that this analogy is risky, and that there are many serious differences between individual, and group intentional states. Yet, I am ready to use it as a picture that provides partial justification of my position. As an ontological individualist, I assume, that it is logically and even sometimes - in cases of small groups - technically possible to explain and predict group intentional states, and behavior solely in terms of intentional states of group members and a group's organizational structure. Yet, as far as larger groups are concerned, this is highly ineffective, time-consuming and requires a huge amount of knowledge. In most cases, when we explain group properties and processes we do not analyze the properties of the realization base, but we take an intentional stance and determine the group's beliefs and desires. Hence, I am ready to agree with proponents of methodological collectivism who argue, that there are explanatory irreducible ${ }^{22}$ grouplevel properties and processes which need to play a role in the explanation of group phenomena (Tollefsen, 2015). This position on group knowledge places itself between radicalism and triviality, for on the one hand, it does not assume the existence of a group agent as a supra-individual entity which is metaphysically over and above the organizational structure of its members. On the other hand, it rejects the trivial summative account according to which a group's intentional states are reducible to the sum of individual beliefs shared on the relevant issue by a majority of group members.

The distributed group knowledge thesis could be expressed in terms of virtue epistemology. Paraphrasing Pritchard's necessary condition, if a group knows that $p$, then the group's true belief that $\mathrm{p}$ is the product of a reliable belief-forming process which is appropriately integrated within the group's cognitive character so that its cognitive success

\footnotetext{
${ }^{21}$ Thanks to an anonymous referee for the AVANT for raising this point.

${ }^{22}$ To be clear I would say: "practically explanatory irreducible."
} 
is to a significant degree creditable to its cognitive agency (Pritchard, 2010). In addition, a group's reliable belief-forming process, its cognitive character, epistemic credit and responsibility are distributed among the group's organizational structure and belong to the whole group, understood as a single cognitive unit. If a group could be recognized as an intentional agent, as the arguments presented in this paper suggest, the first critique mentioned in the previous chapter is invalid.

\subsection{Group as an Epistemic Subject with a Distributed Cognitive Character}

How can virtue epistemology accommodate the idea of a distributed epistemic subject? If knowledge is distributed throughout a system, credit should be assigned to the system as a whole. The second critique points out that an individual within an extended system cannot to a significant degree be credited for an epistemic success because her cognitive artifact, as well as other people, contribute to it to a great extent. If, however, a system's epistemic success can be assigned to its cognitive character, so that the system as a single unit is credited for it, the problem vanishes. The notion of distributed epistemic agency allows us to retain the virtue epistemology approach without worrying about the peripheral role of a subject's epistemic agency in an extended system. This worry is eliminated since the notion of distributed credit enables us to refrain from pointing out a particular part of the system as generating knowledge and to treat a system as a whole as responsible for an epistemic success. Although I doubt whether an extended system composed of one individual can be recognized as a distributed system of knowledge, this notion is widely discussed as far as group agency is concerned (Michaelian, 2014; Kirchhoff \& Newsome, 2012; Green, 2012; Tollefsen, 2006). ${ }^{23}$

Spreading the epistemic credit and cognitive character not only steers us clear of the problem of the peripheral role of epistemic agency in obtaining knowledge, but also constitutes the solution to the third critique presented by Hutchins. If a knowledge-conducive process as well as knowledge itself are not organism-centered but distributed, a system ceases to be static and asocial and becomes reciprocally interrelated with the environment in which it is embedded. The discussion between Clark and Hutchins concerns a one-person extended epistemic subject, whose cognitive abilities, and mental states cannot be easily distributed over the whole system. The reason for this is that an intentional agent cannot be constituted by a person and his cognitive artifact, since only a person can be a subject of intentions, beliefs, desires, doubts, and other propositional states that motivate cognition. I agree with Goldberg on this point. Ascribing such mental states to an agent composed of a person and her cognitive artifact contradicts not only common intuitions, but also common usage of these categories in philosophy. Hence, it is the person who is the subject of

\footnotetext{
${ }^{23}$ The thesis of a distributed subject of knowledge is illustrated by the famous example of collaborative recall studies conducted by the researches under the leadership of John Sutton (Sutton et al., 2010). See also (Barnier, Sutton, Harris, \& Wilson, 2008; Wegner, Giuliano, \& Hertel, 1985) for the researches on The Transactive Memory Systems.
} 
beliefs and cognitive abilities, even though these abilities are extended, for they supervene not only on biological processes taking place inside the human body, but also on nonbiological processes conducted by an artifact and on mutual relations between them all. Now, Clark does not mean to deny that socio-cultural processes are not constitutive for cognitive agency, he says: "cultural practices really do provide me with both a prestructured recipe for success, a well-honed cultural practice (schooling) to help me benefit from that recipe, and a pre-selected set of supporting materials and structures (pen, paper) all ripe for assembly into a new problem-solving whole" (Clark, 2011, p. 459). Yet, this assembly process itself is not maintained by cultural practices, but by the individual, who here and now is the most important element in a wide system composed of a human, cognitive artifact and the socio-cultural practices within which the system is richly embedded.

As far as group agency is concerned, is seems that, unlike wide one-person cognitive systems, certain groups could be recognized as a genuine subject of knowledge. Why is this? The difference between these two kinds of wide cognitive systems is as follows: a group is composed of two or more intentional agents; therefore, it is possible to aggregate their intentions according to a certain strategy so as to obtain a group belief or ability. In the case of a wide one-person cognitive system, this is not possible as there is only one intentional agent who cannot constitute the realization base for the system's beliefs and abilities with anyone else. He is the only subject of the mental states, cognitive abilities, and other epistemic virtues responsible for knowledge.

\section{Conclusion}

The distributed account of group knowledge could be accommodated both by proponents of the bottom-up strategy of explaining group mental states and by advocates of the intentional stance strategy. The difference is that the former focus on determining the base on which group intentional states supervene, while the latter recognizes a group agent as an individual epistemic subject and treats its supervening properties as data for predicting and explaining group behavior. Although the aims of these two strategies are different, I can see no obstacles which could prevent either of them accommodating the distributive account of group knowledge. In the present paper, I argue that virtue epistemology can satisfactorily explain the phenomenon of group knowledge. It fares even better in this respect than with the knowledge of a simple extended system composed of a single individual and a cognitive artifact. To explain group knowledge adequately, virtue epistemology has to be combined with the process-centered account of knowledge as the alternative beliefcentered approach focuses too much on the definition of a group belief and a justificatory reason. I agree with Orestis Palermos that it is the knowledge-conducive process that deserves detailed analysis, not the group belief itself. Group belief is a fascinating and puzzling concept that should be analyzed and debated, but, as far as group knowledge is concerned, its analyses provide no valid understanding of its conditions. Admittedly, the joint account of group justification represented by Tuomela is a theory of group knowledge 
which adequately explains how the members of a group create the group's justifying reason together in the process of joint acceptance. However, this account is limited to rather small groups which are capable of conducting this process. In complex groups, for example groups of researchers conducting large-scale experiments, there could be no joint reason as the members might not share their individual knowledge and might not know the justification for the group's belief. Thus, it is more effective to interpret the group epistemic subject as a single intentional unit and to evaluate its beliefs using the methods of individual epistemology. The explanatory power of the group knowledge thesis which combines virtue reliabilism with the distributed account of group epistemic subjectivity encourages the inclusion of the problem of group knowledge as one of the standard questions of individual epistemology. In concluding his paper "Active Externalism, Virtue Reliabilism, and Scientific Knowledge," Palermos notices that this strategy leads to a unified epistemological theory which accommodates two kinds of individual epistemic subjectssingle-human and distributed-group — and I cannot help but agree with that.

\section{Bibliography}

Baker, L. R. (1995). Explaining attitudes: A practical approach to the mind. Cambridge, UK: Cambridge University Press.

Barnier, A. J., Sutton, J., Harris, C. B., \& Wilson, R. A. (2008). A conceptual and empirical framework for the social distribution of cognition: The case of memory. Cognitive Systems Research, 9(1-2), $33-51$.

Bratman, M. (1999). Faces of intention: Selected essays on intention and agency. Cambridge, UK: Cambridge University Press.

Clark, A. (2008). Supersizing the mind: Embodiment, action and cognitive extension. Oxford, UK: Oxford University Press.

Clark, A. (2007). Curing cognitive hiccups: A defense of the extended mind. The Journal of Philosophy, 54, 163-192.

Clark, A., \& Chalmers, D. (1998). Extended mind. Analysis, 58, 7-19.

Chemero, A. (2009). Radical embodied cognitive science. Cambridge, MA: MIT Press.

Gettier, E. L. (1963). Is justified true belief knowledge? Analysis, 23, 121-23.

Giere, R. N. (2007). Distributed cognition without distributed knowing. Social Epistemology, 21(3), 313-320.

Giere, R. N., \& Moffatt, B. (2003). Distributed cognition: Where the cognitive and the social merge. Social Studies of Science, 33(2), 301-310.

Gilbert, M. (1987). Modeling collective belief. Synthese, 73, 185-204.

Gilbert, M. (1996). Living together: Rationality, sociality, and obligation. Lanham, MD: Rowman and Littlefield. 
Golberg, S.C. (2012). Epistemic extendedness, testimony and the epistemology of instrument-based belief. Philosophical Explorations, 15(2), 181-197.

Goldman, A. (1979). What is justified belief? In G. S. Pappas (Ed.), Justification and knowledge (pp. 1-25). Dordrecht, The Netherlands: Reidel.

Green, A. (2012). Extending the credit theory of knowledge. Philosophical Explorations, 15, 121-132.

Greco, J. (1999). Agent reliabilism. In J. Tomberlin (Ed.), Philosophical perspecives (pp. 273-296). Atascadero, CA: Ridgeview Publishing Co.

Greco, J. (2007). The nature of ability and the purpose of knowledge. Philosophical Issues, 17, 57-69.

Hutchins, E. (1996). Cognition in the wild. Cambridge, MA: MIT Press.

Hutchins, E. (2011). Enculturating the supersized mind. Philosophical studies, 152(3), 437-446.

Kelp, C. (2014). Epistemology extended. Philosophical Issues, 24(1), 230-252.

Kim, J. (1988). Explanatory realism, causal realism, and explanatory exclusion. Midwest Studies in Philosophy, 12(1), 225-239.

Kirchhoff, M. D., \& Newsome, W. (2012). Distributed cognitive agency in virtue epistemology. Philosophical Explorations, 15(2), 165-180.

Knorr-Cetina, K. K. (1999). Epistemic cultures: How the sciences make knowledge. Cambridge, MA: Harvard University Press.

Lackey, J. (2007). Why we don't deserve credit for everything we know? Synthese, 158(3), 345-361.

List, C., \& Pettit, P. (2011). Group agency: The possibility, design and status of corporate agents. Oxford: Oxford University Press.

Menary, R. (2007). Cognitive integration: Mind and cognition unbounded. Basingstoke, UK: Palgrave Macmillan.

Michaelian, K. (2014). JFGI: From distributed cognition to distributed reliabilism. Philosophical Issues, 24(1), 314-346.

Palermos, S. O. (2014a). Knowledge and cognitive integration. Synthese, 191(8), 1931-1951.

Palermos, S. O. (2014b). Loops, constitution, and cognitive extension. Cognitive Systems Research, $27,25-41$.

Palermos, S. O. (2015). Active externalism, virtue reliabilism, and scientific knowledge. Synthese, 192(9), 2955-2986.

Palermos, S. O. (2016a). Spreading the credit: Virtue reliabilism and weak epistemic anti-individualism. Erkenntnis, 81(2), 305-334.

Palermos, S. O. (2016b). The distribution of epistemic agency. In P. J. Reider (Ed.), Social epistemology and epistemic agency: De-centralizing epistemic agency. Lanham, MD: Rowman \& Littlefield International.

Palermos, S. O., \& Pritchard, D. (2013). Extended knowledge and social epistemology. Social Epistemology Review and Reply Collective, 2(8), 105-120.

Pettit, P. (2007). Rationality, reasoning and group agency. Dialectica, 61, 495-519. 
Plantinga, A. (1993). Warrant and proper function. New York, NY: Oxford University Press.

Pritchard, D. (2006). What is this thing called knowledge? New York, NY: Routledge.

Pritchard, D. (2010). Cognitive ability and the extended cognition thesis. Synthese, 175(1), 133-151.

Quinton, A. (1975-1976). Social objects. Proceedings of the Aristotelian Society, 75, 1-27.

Rowlands, M. (1999). Body in mind. Cambridge, UK: Cambridge University Press.

Sosa, E. (2007). A virtue epistemology: Apt belief and reflective knowledge. Oxford, UK: Clarendon Press.

Sterelny, K. (2010). Minds: Extended or scaffolded? Phenomenology and the Cognitive Sciences, 9(4), 465-481.

Sutton, J., Harris, C. B., Keil, P. G., \& Barnier, A. J. (2010). The psychology of memory, extended cognition, and socially distributed remembering. Phenomenology and the Cognitive Sciences, 9(4), 521-560.

Szanto, T. (2014). How to share a mind: Reconsidering the group mind thesis. Phenomenology and the Cognitive Sciences, 13, 99-120.

Theiner, G. (2011). Res cogitans extensa: A philosophical defense of the extended mind thesis. Bern, Switzerland: Peter Lang.

Theiner, G., \& O'Connor, T. (2010). The emergence of group cognition. In A. Corradini, \& T. O'Connor (Eds.), Emergence in science and philosophy (pp. 6-78). New York, NY: Routledge.

Tollefsen, D. (2002). Organizations as true believers. Journal of Social Philosophy, 33, 395-410.

Tollefsen, D. (2004). Collective epistemic agency. Southwest Philosophy Review, 20, 55-66.

Tollefsen, D. (2015). Groups as agents. Malden, MA: Polity Press.

Trybulec, B. (2014a). Extended cognitive system and epistemic subject. Studies in Logic Grammar, and Rhetoric, 40(53), 111-128.

Trybulec, B. (2014b). Umysł zakorzeniony czy rozszerzony? Napięcie w teorii poznania usytuowanego. Filozofia i nauka. Studia filozoficzne interdyscyplinarne, 2, 185-197.

Trybulec, B. (2015a). Grupa jako podmiot stanów mentalnych - indywidualizm a obiektywizm. Zagadnienia Naukoznawstwa, 2(204), 147-156.

Trybulec, B. (2015b). Gdzie przebiegają procesy poznawcze? Teza umysłu rozszerzonego i jej internalistyczna krytyka. Filozofia Nauki, 3(91), 5-19.

Trybulec, B. (2016). O czym myśli Microsoft. Kontrowersje wokół grupowego podmiotu poznania. Filozofia i Nauka. Studia filozoficzne i interdyscyplinarne, 4, 141-157.

Tuomela, R. (2011). An account of group knowledge. In H. Bernhard, D. Sirtes, \& M. Weber, (Eds.), Collective epistemology, Frankfurt, Germany: Ontos Verlag.

Tuomela, R. (1992). Group beliefs. Synthese, 91, 285-318.

Wegner, M., Giuliano, T., \& Hertel, P. (1985). Cognitive interdependence in close relationships. In W. J. Ickes (Ed.), Compatible and incompatible relationships (pp. 253-276). New York, NY: Springer-Verlag. 
Wilson, R. (2001). Group level cognition. Philosophy of Science, 68(3), 262-273.

Wilson, R. (2004). Boundaries of the mind: The individual in the fragile sciences. Cambridge, UK: Cambridge University Press.

Vaesen, K. (2011). Knowledge without credit, exhibit 4: Extended cognition. Synthese, 181(3), 515-529.

Velleman, J. D. (1997). How to share an intention. Philosophy and Phenomenological Research, 57(1), 29-50. 